\title{
Pilot-scale outdoor production of Scenedesmus sp. in raceways using flue gases and centrate from anaerobic digestion as the sole culture medium
} \author{
Emilio Molina Grima, ${ }^{\mathrm{b}, *}$ \\ a Laboratory of Environmental Bioprocesses, Sfax Centre of Biotechnology, University of Sfax, P.O. Box 1177, 3018 Sfax, Tunisia \\ ${ }^{\mathrm{b}}$ Chemical Engineering Department, University of Almería, 04120 Almería, Spain \\ ' Institute of Ecology, Carretera Antigua a Coatepec 351, El Haya, Xalapa 91070, Veracruz, Mexico
}

Ahlem Jebali $^{\mathrm{a}, \mathrm{b}}$, F. Gabriel Acién ${ }^{\mathrm{b}}$, Erika Rodriguez Barradas ${ }^{\mathrm{c}}$, Eugenia J. Olguín ${ }^{\mathrm{c}}$, Sami Sayadi ${ }^{\mathrm{a}}$,

\section{A R T I C L E I N F O}

\section{Keywords:}

Centrate

Outdoor pilot scale raceways

Biomass productivity

Nutrient removal

Lipid productivity

\begin{abstract}
A B S T R A C T
This work investigated the production of Scenedesmus sp. in semi-continuous mode in three pilot-scale outdoor raceways $\left(7.2 \mathrm{~m}^{2}\right)$ using flue gas for $\mathrm{CO}_{2}$ supply and centrate from the anaerobic digestion of urban wastewater as the sole nutrient source. Experiments were performed at different culture depths, 5, 10 and $15 \mathrm{~cm}$, while evaluating two centrate concentrations $(30 \%$ and $45 \%)$ at dilution rates of 0.2 and $0.3 \mathrm{~d}^{-1}$. Under optimal conditions of $30 \%$ centrate, $0.3 \mathrm{~d}^{-1}$ dilution rate and a $15 \mathrm{~cm}$ culture depth, a maximum biomass productivity of $22.9 \mathrm{~g} \mathrm{~m}^{-2} \mathrm{~d}^{-1}$ was obtained. The optical properties of the cultures were studied and the results showed a photosynthetic efficiency of up to $2.0 \%$ and a quantum yield of $0.3 \mathrm{~g}_{\text {biomass }} \mathrm{E}^{-1}$. Nitrogen and phosphorus removal rates of $3 \mathrm{~g} \mathrm{~N} \mathrm{~m}^{-2} \mathrm{~d}^{-1}$ and $0.6 \mathrm{~g} \mathrm{P} \mathrm{m}^{-2} \mathrm{~d}^{-1}$ were recorded, respectively. Lipid productivity of $2.3 \mathrm{~g} \mathrm{~m}^{-2} \mathrm{~d}^{-1}$ was determined possessing a suitable fatty acids profile for biofuel production.
\end{abstract}

\section{Introduction}

Producing treated water that can be safely released into water bodies in the environment is currently an important issue for urban wastewater treatment plants. Conventional wastewater treatment technologies are mainly based on the activated sludge process, which often has drawbacks such as inefficiency, with only a fraction of the total nitrogen and phosphorus present in the effluent being removed (Cabanelas et al., 2013a; Pittman et al., 2011) as well as high operational costs of up to $0.2 € / \mathrm{m}^{3}$ (Arbib et al., 2014; Pittman et al., 2011). Considering the detrimental environmental impact of wastewater released into aquatic ecosystems, principally the eutrophication risk (Pittman et al., 2011), the urgent need to improve the treatment approach is recognized. Microalgae-based processes offer a promising option for an eco-friendly wastewater bioremediation process; however, this needs to go hand-in-hand with the production of a valuable co-product, which generates revenue to offset costs (Park et al., 2011). Microalgae can grow in poor quality waters such as wastewater while, at the same time, assimilate inorganic and organic nutrients for growth, thus simultaneously treating the water and producing high-potential biomass (Jebali et al., 2018, 2015; Qi et al., 2018; Zhu et al., 2017; Arbib et al., 2014; Rawat et al., 2011). Such a combined process could counterbalance the operational costs related, firstly, to conventional wastewater treatment system costs due to their high energy consumption up to $0.5 \mathrm{kWh} / \mathrm{m}^{3}$ (personal communication from Aqualia), and secondly, to mass microalgae production, which currently uses expensive, non-sustainable artificial fertilizers in the culture medium (Zhu and Hiltunen, 2016). This coupling approach could help to increase the feasibility of using microalgae in low-value products. In fact, various studies have pointed out that mass microalgae commercialization in this field is impeded by the upstream and downstream processing costs (Zhu et al., 2017; Park et al., 2013; Chisti, 2012; Park et al., 2011), making the whole process non cost-effective. For instance, pure $\mathrm{CO}_{2}$ supply can account for $30 \%$ of the microalgae production cost (Acién Fernández et al., 2013); this, however, could be reduced by using flue gas instead (Chiu et al., 2011). Additionally, life cycle analysis research conducted by Yang et al. (2011) concluded that up to $90 \%$ of the freshwater could be saved by using wastewater for microalgae cultivation; while $94 \%$ and $100 \%$ of nitrogen and micronutrient requirements, respectively, could be provided using wastewater. Microalgal production integrated with wastewater treatment and $\mathrm{CO}_{2}$ mitigation is still not commercialized, although the relevant costs can be reduced. The resulting microalgae biomass could be applied as a feedstock to produce biofertilizers, biohydrogen, biodiesel, bio-oil, bio-materials and other biochemical derivatives (Rinna et al., 2017; Cabanelas et al., 2013b; Park et al., 2013; Rawat et al., 2011).

\footnotetext{
* Corresponding author.

E-mail address: emolina@ual.es (E. Molina Grima).
} 
Centrate is obtained from the digested sludge dewatering process after the anaerobic digestion of secondary treated urban wastewater. It is considered one of the richest urban wastewater nutrient streams resulting in higher biomass productivity (Li et al., 2011; Wang et al., 2010). Numerous studies have reported the robustness and tolerance of several microalgae strains to centrate as the culture medium, most notably those of the genera Scenedesmus and Chlorella. However, most of these studies were conducted at laboratory scale (Li et al., 2011, Sepúlveda et al., 2015; Zhou et al., 2012b); few confirmed the results obtained at the large scale and in semi-continuous mode (Min et al., 2011; Morales-Amaral et al., 2015a); nor did they investigate one of the key operational parameters, namely, the appropriate culture depth to use.

The aim of this work is to investigate the feasibility of producing microalgae using centrate as the culture medium and flue gas for $\mathrm{CO}_{2}$ supply. For this, the native strain Scenedesmus sp. was selected as it previously showed robustness and tolerance to this wastewater. Experiments were carried out under real outdoor conditions in three pilot scale raceway reactors to assess the reliability of the process. In this respect, key operational parameters, namely different dilution rates $\left(0.2 \mathrm{~d}^{-1}\right.$ and $\left.0.3 \mathrm{~d}^{-1}\right)$, centrate percentages ( $30 \%$ and $\left.45 \%\right)$ and culture depths $(5,10$ and $15 \mathrm{~cm})$ were studied to achieve maximum process performance. Thus, the effect of these parameters on biomass productivity, nutrient removal capacity, lipid content and the fatty acids profile was evaluated. In addition, the biomass optical properties were studied to assess the cultures' light-use efficiency.

\section{Materials and methods}

\subsection{Microorganism and culture media}

The freshwater isolate Scenedesmus sp. was used in this study after previously being selected as a potentially suitable strain for wastewater treatment (Jebali et al., 2015). The strain inoculum was maintained at $25{ }^{\circ} \mathrm{C}$ under continuous aeration and illumination of $80 \mu \mathrm{E} \mathrm{m}^{-2} \mathrm{~s}^{-1}$ using MDM medium (Ichimura and Itoh, 1977). Centrate from the urban wastewater treatment plant in Almería (Spain) was used as the culture medium for the experiments. Experimental culture media were prepared by mixing tap water with centrate at different percentages: $30 \%$ and $45 \% \mathrm{v} / \mathrm{v}$. Centrate is a wastewater stream that has a high nutrient concentration; it is obtained from the digested sludge dewatering process following the anaerobic digestion of treated urban wastewater. The composition of the centrate used is given in Table 1. The medium was prepared daily by using a greenhouse irrigation system (Nutritec 9000, Ritec, Riegos y Tecnología S.L., Spain). It was firstly subjected to ozonization and then passed through 200 and $25 \mu \mathrm{m}$ filters.

\subsection{Reactors and operational conditions}

Experiments were performed outdoors in three pilot-scale raceway

Table 1

Composition of the centrate obtained from a real urban wastewater treatment plant used for preparing the different culture media.

\begin{tabular}{|c|c|c|c|}
\hline Parameter & $\mathrm{mg} / \mathrm{L}$ & Parameter & $\mathrm{mg} / \mathrm{L}$ \\
\hline TSS & $0.12 \pm 0.08$ & Boron & 0.6 \\
\hline $\mathrm{N}-\mathrm{NH}_{4}{ }^{+}$ & $628.05 \pm 60.66$ & Calcium & 27 \\
\hline $\mathrm{N}-\mathrm{NO}_{3}{ }^{-}$ & $7.17 \pm 2.64$ & Magnesium & 22 \\
\hline${\mathrm{P}-\mathrm{PO}_{4}{ }^{3-}}^{-}$ & $64.03 \pm 26.23$ & Sulfate & 31 \\
\hline TOC & $182.67 \pm 69.58$ & Potassium & 241 \\
\hline TIC & $563.10 \pm 131.18$ & Iron & 0.51 \\
\hline Carbonate & 20 & Copper & $<0.20$ \\
\hline Bicarbonate & 1523 & Manganese & $<0.10$ \\
\hline Sodium & 234 & Zinc & 0.15 \\
\hline
\end{tabular}

$\mathrm{pH}=7.53 \pm 0.19 ;$ Conductivity $=5.80 \pm 0.96 \mathrm{~ms} / \mathrm{cm}$. reactors, $7.2 \mathrm{~m}^{2}$ in area each. The reactors consisted of polyethylene algal ponds, channels $5.0 \mathrm{~m}$ in length and $0.6 \mathrm{~m}$ wide connected by $180^{\circ}$ bends. Culture circulation is ensured by a paddlewheel, $0.6 \mathrm{~m}$ in diameter, rotating at $0.3 \mathrm{~m} / \mathrm{s}$ and regulated by an electric motor (Ebarba, Barcelona, Spain); the speed was regulated by a frequency inverter (Yaskawa AC Drive V1000, Yaskawa Electric Europe GmbH, Germany). The $\mathrm{pH}$ was maintained in the 7.8-8.0 range by on-demand $\mathrm{CO}_{2}$ injection coming from flue gas (with an average $\mathrm{CO}_{2}$ concentration of $10 \%$ ); this was obtained from a diesel heating boiler. The flue gas at the boiler outlet was cooled by passing through a passive stainless steel serpentine; it then went to the compressor for storage. The air and flue gas were sparged at the bottom of the reactor sump through a diffuser. Air was continuously provided to the systems at $0.03 \mathrm{v} / \mathrm{v} / \mathrm{min}$ (FR4L72BVBN flow meters, Key Instruments, USA) to ensure dissolved oxygen removal. The parameters for temperature, $\mathrm{pH}$ and dissolved oxygen concentration were measured by probes $(5342 \mathrm{pH}$ electrode and 5120 OD electrode, Crison Instruments S.A., Spain) connected to MM44 transmitter units (Crison Instruments, Spain) which were controlled online. The impinging irradiance was measured by a thermoelectric pyranometer connected to an AC-420 adapter (LP-02, Geónica S.A., Spain). The data for all of these parameters were logged using DaqFactory 5.0 software (Azeotech Inc., USA). The medium inlet flow rate was regulated by flow meters (FCIV0201D, 10100, FIP, Italy).

The raceway reactors were operated at 3 different culture depths $(0.05,0.10$ and $0.15 \mathrm{~m}$, corresponding to culture volumes of 360,720 and $1080 \mathrm{~L}$, respectively) and two different centrate concentrations (30\% and $45 \%$ ) and dilution rates $0.2 \mathrm{~d}^{-1}$ and $0.3 \mathrm{~d}^{-1}$. Experiments were firstly performed in batch mode, where the raceways were inoculated with $10 \%$ of inoculum at the exponential phase of cell density of $1.2 \cdot 10^{7}$ cell mL ${ }^{-1}$, cultivated in an outdoor $100 \mathrm{~L}$ bubble-column photobioreactor. Subsequently, the cultures were shifted to semi-continuous mode by the daily addition of fresh medium during daylight periods (10 a.m-2 p.m) and the same culture volume was harvested in order to achieve dilution rates of $0.2 \mathrm{~d}^{-1}$ and $0.3 \mathrm{~d}^{-1}$. This was performed until steady state was achieved; at this point, a constant biomass concentration was attained. Experiments were conducted during, May, June and July in Almería ( $\left.36^{\circ} 48^{\prime} \mathrm{N}, 2^{\circ} 43^{\prime} \mathrm{W}\right)$, Spain.

\subsection{Biomass concentration and fluorescence measurement}

The optical density of the three cultures at $750 \mathrm{~nm}$ was measured daily using a spectrophotometer (DR/4000 UV/Vis Spectrophotometer, $\mathrm{HACH}, \mathrm{USA}$ ). The dry weight biomass concentration was determined by filtering $100 \mathrm{~mL}$ of each culture through a $1 \mu \mathrm{m}$ pre-dried filter (Macherey-Nagel GmbH \& Co.KG, Germany) and drying it in an oven at $80^{\circ} \mathrm{C}$ until constant weight was obtained.

Additionally, the maximum photosynthetic efficiency of photosystem II, calculated as the Fv/Fm ratio, was measured daily using a fluorometer (AquaPen AP 100, Photon Systems Instruments, Drasov, The Czech Republic) to check the physiological status of the cell. The quantum yield, the extinction coefficient and the average light intensity were calculated as detailed by Molina Grima et al. (1997). The extinction coefficient (Ka) was calculated by dividing the average absorption in the photosynthetically-active radiation range, PAR (400-700 nm), by the biomass concentration (Cb) and the cuvette light path (p) (Eq. (1)):

$K a=\frac{A b s}{C_{b} \times p}$

The average irradiance was calculated as follows (Eq. (2)):

$I_{a v}=\frac{I_{0}}{K_{a} \cdot C_{b} \cdot p}\left(1-\exp \left(-K_{a} \cdot C_{b} \cdot p\right)\right)$

where $I_{0}$ was the irradiance in the absence of cells.

Quantum yield is the amount of microalgal biomass produced by a unit of radiation (moles of photons) absorbed by the culture. This can 
be calculated as follows (Eqs. (3) and (4)):

$F_{v o l}=I_{a v} \cdot K_{a} \cdot C_{b}$

$\Psi_{\mathrm{E}}=\frac{\mathrm{P}_{\mathrm{b}}}{\mathrm{F}_{\mathrm{vol}}}$

where $\mathrm{P}_{\mathrm{b}}$ is the volumetric biomass productivity and $\mathrm{F}_{\mathrm{vol}}$ stands for the photon flux absorbed by a volume unit; it is obtained by multiplying the average irradiance $\left(\mathrm{I}_{\mathrm{av}}\right)$, on a culture volume basis, by the extinction coefficient $\left(\mathrm{K}_{\mathrm{a}}\right)$ and the biomass concentration $\left(\mathrm{C}_{\mathrm{b}}\right)$.

The photosynthetic efficiency (PE) value was obtained by calculating the ratio of energy stored in the produced biomass to the energy impinging on the reactor surface. The biomass combustion heat $(\Delta \mathrm{H})$ was calculated considering the specific caloric value of the lipids $\left(38.9 \mathrm{~kJ} \mathrm{~g}^{-1}\right)$, proteins $\left(24 \mathrm{~kJ} \mathrm{~g}^{-1}\right)$ and carbohydrates $\left(16.6 \mathrm{~kJ} \mathrm{~g}^{-1}\right)$, and by knowing the biochemical composition of the biomass. The ratio of the reactor's volume to surface $(\mathrm{V} / \mathrm{S})$ and the PAR to the global ratio of light, which was $2 \mathrm{E} \mathrm{MJ}^{-1}$, were used for the photosynthetic efficiency calculation as follows (Eq. (5)):

$P E=\frac{P_{b} \cdot \Delta H \cdot V}{I_{0} \cdot S}$

\subsection{Analytical procedure}

The nutrient analyses at the reactor inlet and outlet were carried out using colorimetric methods (Ministry of Agriculture, 1982). The phosphate was measured by visible spectrophotometry through the phospho-vanado-molybdate complex. The nitrate was determined by measuring the optical density at $220 \mathrm{~nm}$ and $275 \mathrm{~nm}$. The ammonium was quantified according to the Nessler method. Nutrient depuration was calculated as follows (Eq. (6)):

Nutrient depuration $=\frac{[\text { Nutrient }]_{\text {inlet }}-[\text { Nutrient }]_{\text {outlet }}}{[\text { Nutrient }]_{\text {inlet }}} \times 100$

At steady state, biomass was harvested by centrifugation at $7500 \mathrm{rpm}$ for $5 \mathrm{~min}$ (SIGMA 4-15 Sartorius, Goettingen, Germany), washed twice with distilled water, freeze dried and used to determine the lipid content. Total lipids were determined as described by Kochert (1978). The fatty acids content and profile were obtained by direct transesterification and gas chromatography (Agilent Technologies 6890 N Series Gas Chromatograph, Santa Clara, CA, USA) as described by Rodríguez-Ruiz et al. (1998).

All the samples were withdrawn from cultures at steady state. All of the analyses were carried out in duplicate and the mean value was reported. Standard deviation ( \pm SD) was calculated using excel tools.

\section{Results and discussion}

\subsection{Culture growth}

To determine the feasibility of the outdoor production of the native microalga Scenedemus sp. in raceway ponds using centrate as the sole nutrient source and flue gas for the $\mathrm{CO}_{2}$ supply, experiments were performed with the reactors operating at a dilution rate of $0.2 \mathrm{~d}^{-1}$ and $0.3 \mathrm{~d}^{-1}$, using centrate diluted with freshwater at different percentages (30\% and $45 \%)$ and operating at three different culture depths (5, 10 and $15 \mathrm{~cm}$ ).

The centrate contains nutrients such as nitrogen and phosphorus in addition to other trace elements that could efficiently support microalgae growth. The centrate exhibited the highest ammonium concentration among the urban wastewater streams (Morales-Amaral et al., 2015b; Osundeko and Pittman, 2014; Zhou et al., 2012a). Numerous studies reported that $\mathrm{N}^{-\mathrm{NH}_{4}}{ }^{+}$is the preferred form for microalgae because its assimilation process does not require the redox reaction, which means a lower energy requirement (Cai et al., 2013). Indeed, it was
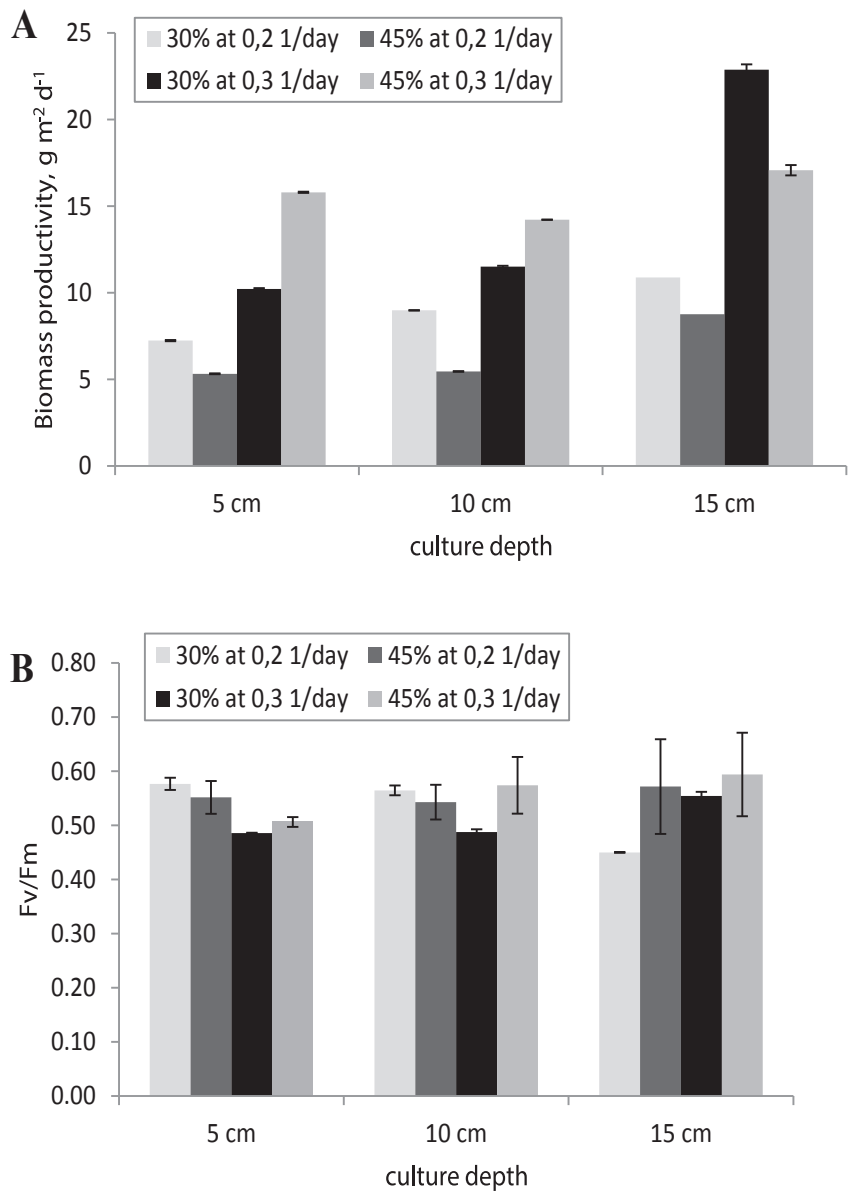

Fig. 1. Variation in biomass productivity (A) and chlorophyll fluorescence (B) of Scenedesmus sp. culture as a function of the centrate percentage and culture depth. Experiments were conducted in semi-continuous mode at $0.2 \mathrm{~d}^{-1}$ and $0.3 \mathrm{~d}^{-1}$.

stated that assimilated inorganic nitrogen forms are reduced to ammonium before being incorporated into amino acids within intracellular fluid (Cai et al., 2013). Furthermore, another study showed that algae start consuming nitrate when ammonium is depleted from the medium (Maestrini et al., 1986).

From May to July, the cultures were subjected to an average impinging irradiance range of $1094.5 \mu \mathrm{Em}^{-2} \mathrm{~s}^{-1}$ (i.e. $238 \mathrm{w} / \mathrm{m}^{2}$ ), equivalent to $470 \mu \mathrm{E} \mathrm{m}^{-2} \mathrm{~s}^{-1}$ (PAR), while the $\mathrm{CO}_{2}$ supply was ensured by injecting flue gas. The temperature of the pond and the dissolved oxygen over the course of the experiment ranged from 13.6 to $26.0^{\circ} \mathrm{C}$ and $131.0 \%$ sat. to $502.4 \%$ sat., respectively (note that $100 \%$ sat correspond to the solubility of $\mathrm{O}_{2}$ in water when it is bubbled with air).

The biomass productivity results under these conditions, as a function of the centrate dilution and the dilution rate for the different culture depths tested, are presented in Fig. 1A. For raceways operating at 5 and $10 \mathrm{~cm}$ culture depths, a further increase in the centrate percentage from $30 \%$ to $45 \%$ led to an increase in biomass productivity. An additional experiment was conducted at $5 \mathrm{~cm}$ and $60 \%$ centrate, which demonstrated that above this centrate percentage, the biomass productivity declined at this depth. On the other hand, for the raceway operated at $15 \mathrm{~cm}, 45 \%$ centrate led to culture inhibition and consequently to a decrease in biomass productivity. This could be more likely related to the increase of ammonium concentration in the medium that entailed culture growth inhibition. In fact, high ammonium concentrations are widely known to negatively affect microalgae growth. For instance, Morales-Amaral et al., (2015b) reported inhibition due to excessive ammonium at a concentration in the order of $200 \mathrm{mg} / \mathrm{L}$ for 
Muriellopsis sp. and Pseudokirchneriella subcapitata cultures operating indoors in semi-continuous mode at $0.3 \mathrm{~d}^{-1}$; He et al. (2013), on the other hand, claimed that $C$. vulgaris growth declined markedly at ammonium concentrations higher than $143 \mathrm{mg} / \mathrm{L}$.

The maximum biomass productivity was $22.9 \mathrm{~g} \mathrm{~m}^{-2} \mathrm{~d}^{-1}$ at the $15 \mathrm{~cm}$ culture depth, at $0.3 \mathrm{~d}^{-1}$ and $30 \%$ centrate. This was far greater than the $4.9 \mathrm{~g} \mathrm{~m}^{-2} \mathrm{~d}^{-1}$ reported for the cultivation of a microalgal consortium in a raceway pond of $950 \mathrm{~L}$ using wastewater predominantly made up of carpet mill effluent mixed by municipal wastewater (Chinnasamy et al., 2010b), the $8.04-10.36 \mathrm{~g} \mathrm{~m}^{-2} \mathrm{~d}^{-1}$ biomass productivity range determined by the cultivation of a microalgae consortium in batch mode using untreated carpet industry effluent in raceway pond at a $18 \mathrm{~cm}$ culture depth of $500 \mathrm{~L}$ volume (Chinnasamy et al., 2010a). However, it was comparable to the $24 \mathrm{~g} \mathrm{~m}^{-2} \mathrm{~d}^{-1}$ obtained from the semi-continuous cultivation of Scenedesmus sp. in $12 \mathrm{~cm}$ deep pilot-scale raceway reactors using 30\% centrate (Morales-Amaral et al., 2015a).

The optimum centrate percentage determined outdoors (30\%) is lower than that determined at the laboratory scale $(60 \%)$ in our previous study (Jebali et al., 2018). This could be explained by the fact that, compared to indoor experiments, outdoor culture conditions are subject to various uncontrollable parameters such as temperature and diurnal light fluctuations over the course of a single day, which might add to the stress on microalgae growth in addition to the high ammonium content in the centrate. Moreover, in this study, the ammonium content reported in the centrate (up to $628 \mathrm{mg} / \mathrm{L}$ ) was too high whereas in the previous study, it was far lower, in the $264-318.7 \mathrm{mg} / \mathrm{L}$ range (Jebali et al., 2018).

In this work, the effect of two dilution rates $\left(0.2 \mathrm{~d}^{-1}\right.$ and $\left.0.3 \mathrm{~d}^{-1}\right)$ on strain performance was investigated (Fig. 1A). For all of the centrate concentrations tested and the different culture depths studied, one can observe that the higher the dilution rate, the higher the biomass productivity. This would be explained by the fact that the culture optimal growth conditions were attained at $0.3 \mathrm{~d}^{-1}$ dilution rate. Thus, an adequate adjustment of the optimal dilution rate to be applied is very critical to maximize biomass productivity. Indeed, various studies have concluded that continuous culture systems allow the biomass productivity to be maximized by operating the optimal process parameter combination, which is closer to that for optimal microalgae production (McGinn et al., 2012; Osundeko and Pittman, 2014). It is worth mentioning that the optimum dilution rate, determined here at $0.3 \mathrm{~d}^{-1}$, was in accordance with the results obtained in our previous study with Scenedesmus sp. using indoor open raceway-simulating reactors (Jebali et al., 2018).

The optimum culture depth determined in this outdoor study is in agreement with our previous results at the laboratory scale using raceway-simulating reactors, where $15 \mathrm{~cm}$ was the recommended culture depth to be used (Jebali et al., 2018). It should be pointed out that the culture depth is an important operational feature that affects $\mathrm{CO}_{2}$ loss in the raceway pond (Rawat et al., 2011) as well as the light availability inside the reactor; and consequently the effective light use by microalgae to maximize photosynthetic activity (Sutherland et al., 2014). In fact, light plays a determining role in microalgae productivity through photosynthesis, when inorganic nutrients are converted to organic molecules and, ultimately, to biomass, which is a form of stored chemical energy. In dense cultures, light intensity decreases exponentially from the illuminated surface to the bottom of the reactor due to light attenuation and mutual shading (Acién Fernández et al., 2013; Sutherland et al., 2015, 2014), where cells move from one position to another receiving modulated light (Acién Fernández et al., 2013). Thus, it has been claimed that culture depth, along with biomass concentration and the turbulence regime, determine the light availability to the cell and the degree of light attenuation (Sutherland et al., 2014).

The measurement of the maximum quantum yield of photosynthesis, which reflects the maximal photochemical efficiency of photosystem II (Fv/Fm) (Fig. 1B) revealed the culture's tolerance to centrate
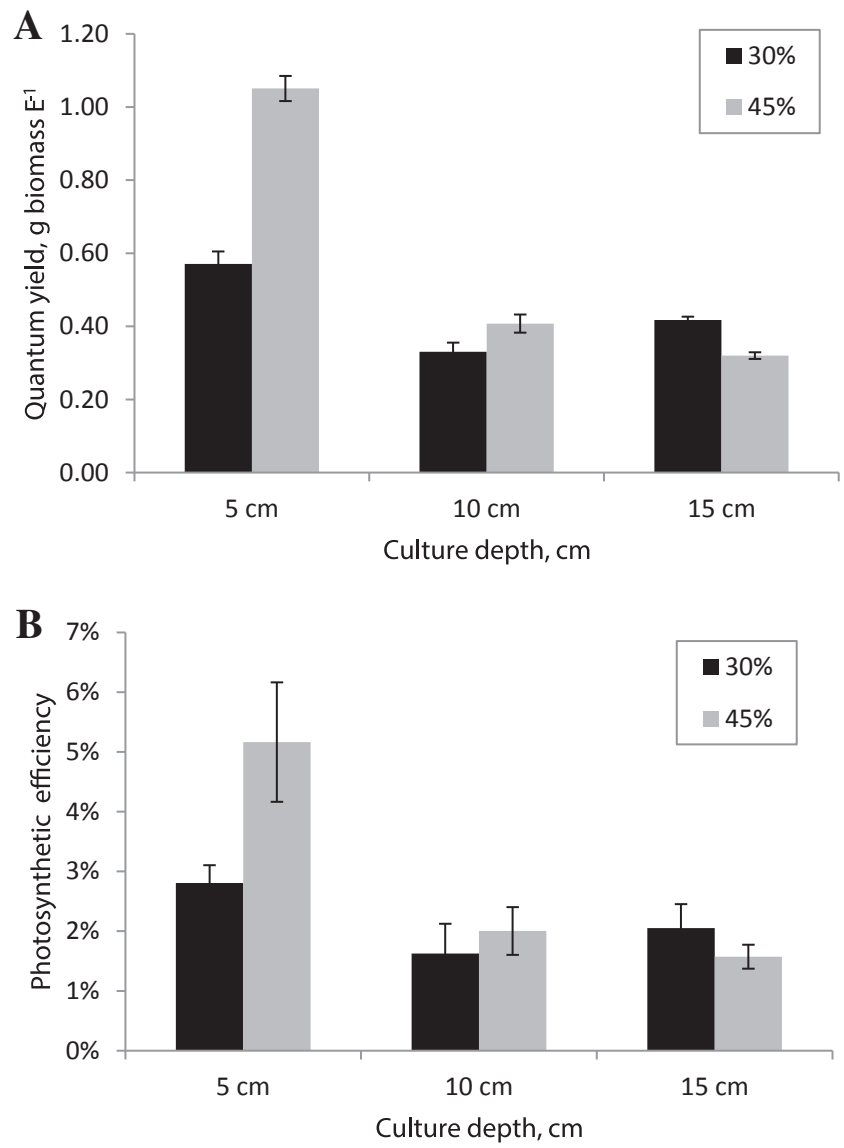

Fig. 2. Effect of centrate percentage in the culture medium and culture depth $(5,10$ and $15 \mathrm{~cm})$ on quantum yield (A) and photosynthetic efficiency (B) in semi-continuously fed Scenedesmus sp. culture at $0.3 \mathrm{~d}^{-1}$.

as the culture medium as well as the culture's adaptation to outdoor conditions. It is worth noting that bacteria and other Chlorophyceae microalgae strains were observed by microscopic observations; however, the strain with which the reactors were inoculated was predominant.

The results obtained here prove that centrate can be an effective nutrient source option mitigating the otherwise high operational costs for culture mediums reported in large-scale microalgae cultivation. Additionally, our results showed that the cultures were tolerant to flue gas even though it contains a mixture of gases, some of which are potentially toxic to microalgae (e.g. $\mathrm{NO}_{\mathrm{x}}$ and $\mathrm{SO}_{\mathrm{x}}$ ). This suggests that microalgae offer a promising bio-based alternative for $\mathrm{CO}_{2}$ sequestration, one of the main greenhouse gases (GHGs) emitted into the atmosphere (Chiu et al., 2011).

The results for the optical properties of the culture are presented in Fig. 2. For the quantum yield, this was maximal up to $1.0 \mathrm{~g} \mathrm{E}^{-1}$ using $45 \%$ centrate and a $5 \mathrm{~cm}$ culture depth; it reduced to $0.3 \mathrm{~g} \mathrm{E}^{-1}$ at $45 \%$ centrate and a $15 \mathrm{~cm}$ culture depth indicating low light-use efficiency under these conditions (Fig. 2A). The marine strain $N$. gaditana reached a maximal value of $1.3 \mathrm{~g} \mathrm{E}^{-1}$ using centrate as the culture medium under laboratory conditions (artificial light) (Sepúlveda et al., 2015). The photosynthetic efficiency (Fig. 2B) was greater at low culture depths: efficiency of up to $5.2 \%$ was recorded at a $5 \mathrm{~cm}$ culture depth and $45 \%$ centrate. Morales-Amaral et al. (2015a) reported a maximal photosynthetic efficiency of $9 \%$ from semi-continuously fed culture performed in thin-layer reactor of $2 \mathrm{~cm}$ culture depth. Furthermore, the results showed maximum light availability, $262.6 \mu \mathrm{E} \mathrm{m}^{-2} \mathrm{~s}^{-1}$, at a culture depth of $15 \mathrm{~cm}$ and $45 \%$ centrate; this decreased to $125.5 \mu \mathrm{E} \mathrm{m}^{-2} \mathrm{~s}^{-1}$ at a $15 \mathrm{~cm}$ culture depth and $30 \%$ centrate due to the high biomass concentration under these optimal growth conditions. 


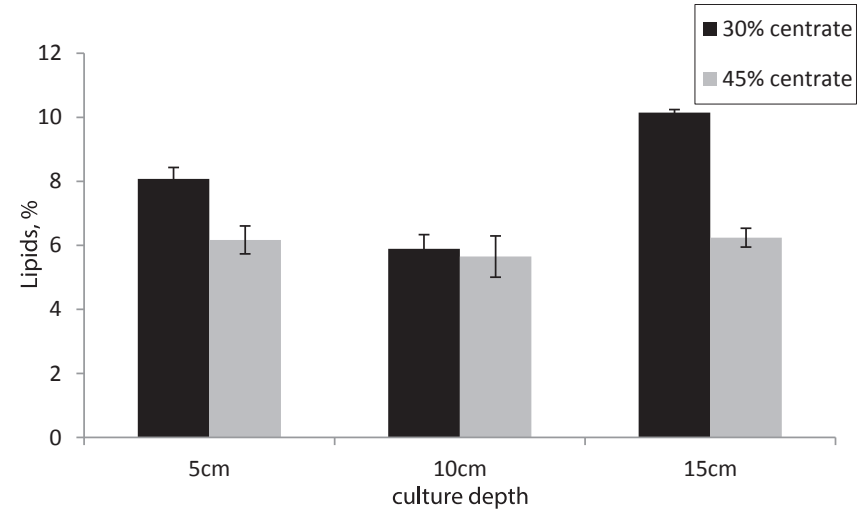

Fig. 3. Variation in the lipid content of semi-continuously cultivated Scenedesmus sp. at a $0.3 \mathrm{~d}^{-1}$ dilution rate as a function of the culture depth and centrate percentage.

Similarly, Sepúlveda et al. (2015) observed light availability decrease within the optimal centrate percentage range for $N$. gaditana growth using centrate. The extinction coefficient was maximal $\left(0.13 \mathrm{~m}^{2} \mathrm{~g}^{-1}\right)$ at $30 \%$ centrate and a $15 \mathrm{~cm}$ culture depth but reduced to $0.06 \mathrm{~m}^{2} \mathrm{~g}^{-1}$ when using $45 \%$ centrate and a $5 \mathrm{~cm}$ culture depth, meaning that more light had to be available under these conditions. These results fell within the range of values obtained by Morales-Amaral et al. (2015a).

\subsection{Lipid content and fatty acids profile}

With respect to the biomass produced, the lipid content and fatty acids profile at $0.3 \mathrm{~d}^{-1}$ were analyzed. Fig. 3 shows the variation in lipid content with the centrate percentage in the medium and the culture depth. The results revealed that no particular tendency was seen with regard to the centrate percentage and culture depth. The highest amount of lipids, $10.1 \%$, which corresponded to a lipid productivity of $2.3 \mathrm{~g} \mathrm{~m}^{-2} \mathrm{~d}^{-1}$, was determined in the $15 \mathrm{~cm}$-deep pond using $30 \%$ centrate. The relatively low lipid contents obtained (Fig. 3) revealed that the centrate as culture medium was not stressful enough to trigger lipid production by microalgae which confirm the recorded data from chlorophyll fluorescence $(\mathrm{Fv} / \mathrm{Fm})$ that showed an adaptation and tolerance of the strain to this kind of wastewater. This was within lipid productivity range $\left(8.3-15.8 \mathrm{mg} \mathrm{Ld}^{-1}\right.$ ) determined by Rinna et al. (2017) who cultivated Botryococcus braunii strains in artificial medium, pre-treated and treated domestic wastewater and within the $8.1 \%$ range determined from Scenedesmus obliquus cultivation using urban wastewater in an outdoor tubular vertical photobioreactor (Batista et al., 2015). It was claimed that high lipid percentages were not usually observed in open pond microalgae cultivation; in particular, under wastewater conditions (Pittman et al., 2011), and that one should focus on high microalgae biomass productivity leading to significant total lipid productivity, which is preferable for a large-scale production system (Pittman et al., 2011).

The fatty acids profile is given in Table 2 . The contents ranged from $2.3 \%$ d.wt. to $4.5 \%$ d.wt. with no particular trend observable as a function of the depth whereas it did decrease as the centrate percentage increased in the medium. The short-chain fatty acids C16:0, C18:0, C18:1n7 and C18:3n 3 predominated - with a maximum $20.0 \%$ (of total fatty acids) obtained at a $15 \mathrm{~cm}$ pond depth and $30 \%$ centrate; $17.6 \%$ (of total fatty acids) at a $15 \mathrm{~cm}$ pond depth and $45 \%$ centrate; $21.5 \%$ (of total fatty acids) at a $5 \mathrm{~cm}$ pond depth and $60 \%$ centrate and $31.4 \%$ (of total fatty acids) at a $5 \mathrm{~cm}$ pond depth and $45 \%$ centrate, respectively. These fatty acid classes were similarly reported elsewhere but in different percentages, probably due to the culture conditions and differences in wastewater composition (Jebali et al., 2015; Ji et al., 2013; Sydney et al., 2011).The content of the monosaturated fatty acids C16:1 and $\mathrm{C} 18: 1$ ranged from $34.0 \%$ to $18.0 \%$ (of total fatty acids). It has been
Table 2

Variation in the fatty acids profile of the Scenedesmus sp. culture in semi-continuous mode at $0.3 \mathrm{~d}^{-1}$ as a function of the centrate percentage in the medium and the culture depth.

\begin{tabular}{|c|c|c|c|c|c|c|}
\hline \multirow[t]{2}{*}{ F.A } & \multicolumn{2}{|c|}{$15 \mathrm{~cm}$ pond depth } & \multicolumn{2}{|c|}{$10 \mathrm{~cm}$ pond depth } & \multicolumn{2}{|c|}{$5 \mathrm{~cm}$ pond depth } \\
\hline & $30 \%$ & $45 \%$ & $30 \%$ & $45 \%$ & $30 \%$ & $45 \%$ \\
\hline $16: 0$ & 20.04 & 17.30 & 17.39 & 18.32 & 18.58 & 16.80 \\
\hline 16:1n7 & 3.65 & 6.50 & 3.87 & 6.32 & 2.44 & 4.19 \\
\hline $16: 2 \mathrm{n} 4$ & 4.56 & 2.94 & 3.78 & 4.38 & 3.17 & - \\
\hline $16: 3 \mathrm{n} 4$ & 8.56 & - & - & - & 4.83 & 7.70 \\
\hline $16: 4 \mathrm{n} 1$ & 3.49 & 8.33 & 6.24 & 6.65 & 9.01 & 8.20 \\
\hline 18:0 & 5.75 & 17.60 & 5.09 & 3.71 & 4.57 & 2.71 \\
\hline 18:1n9 & 3.66 & 3.66 & - & - & 4.34 & 13.17 \\
\hline 18:1n7 & 13.46 & 10.78 & 16.10 & 17.51 & 16.78 & - \\
\hline $18: 3 \mathrm{n} 3$ & 24.02 & 19.54 & 30.72 & 25.57 & 20.55 & - \\
\hline FA, \%d.wt & 2.59 & 3.05 & 3.24 & 2.36 & 4.43 & 4.28 \\
\hline
\end{tabular}

widely reported that these monosaturated fatty acids are favorable for high-quality biofuel production in terms of their cetane number, oxidative stability and cold flow characteristics (Biller and Ross, 2011; Hoekman et al., 2012).

\subsection{Nutrient removal capacity of Scenedesmus sp.}

Nutrient elimination processes in wastewater treatment systems can be biotic or abiotic mechanisms (Qi et al., 2018; Matamoros et al., 2015; Min et al., 2014). In this work, nitrogen and phosphorus in the inlet and outlet at steady state were analyzed in order to evaluate nutrient removal under the different cultivation conditions tested. Fig. 4A shows the variation in nitrate at the inlet and outlet, respectively, for $30 \%$ and $45 \%$ centrate as a function of the culture depth at $0.3 \mathrm{~d}^{-1}$ dilution rate. The results indicate that a nitrification phenomenon possibly took place in some of the assays, where the final nitrate concentration increased compared to the initial concentration. The highest nitrate outlet rate $(9.1 \mathrm{mg} / \mathrm{L})$ was observed at $0.3 \mathrm{~d}^{-1}$ at a $5 \mathrm{~cm}$ culture depth and with $30 \%$ centrate. This nitrification is due to the transformation of ammonium to nitrite by Nitrosomonas bacteria, and then to nitrate by Nitrobacter bacteria (Ruiz-Martinez et al., 2012). This phenomenon would imply that microalgae growth and consequently nitrogen up-take was lower than the growth of existing bacteria in the culture.

Fig. 4B shows the influence of the centrate percentage and the culture depth on the ammonium outlet concentration at $0.3 \mathrm{~d}^{-1}$. The results revealed that the higher the inlet ammonium loading, the greater the outlet ammonium concentration. The culture depth had an effect on the final ammonium concentration, increasing as the culture depth increased. In addition, one can observe that, when using $45 \%$ centrate, the removal efficiency was enhanced, where the highest (94\%) was determined at a $5 \mathrm{~cm}$ culture depth, higher than $77.8 \%$ obtained from the co-culture of microalgae and bacteria using fermentation wastewater as culture medium (Qi et al., 2018). In fact, it was previously stated that these parameters - pond depth and hydraulic retention time (note that dilution rate is the inverse of the hydraulic retention time) - are key operational features to adjust the culture density and improve light availability in the pond while avoid selfshading (Park et al., 2011). It is worth pointing out that ammonium volatilization possibly contributed to nitrogen removal for open outdoor cultivation though the control of $\mathrm{pH}$ and temperature. The data showed that no relevant values were recorded.

Regarding nitrogen removal rate, it can be observed that, in line with the biomass productivity results, the removal rate increased as the culture depth increased (Fig. 4C). Moreover, the higher the centrate percentage in the medium, the greater was the removal rate - the maximum obtained $\left(5.2 \mathrm{~g} \mathrm{~N} \mathrm{~m}^{-2} \mathrm{~d}^{-1}\right.$ or $\left.34.7 \mathrm{mg} \mathrm{N} \mathrm{L}^{-1} \mathrm{~d}^{-1}\right)$ was with a $15 \mathrm{~cm}$ pond depth at $0.3 \mathrm{~d}^{-1}$ and $45 \%$ centrate. 

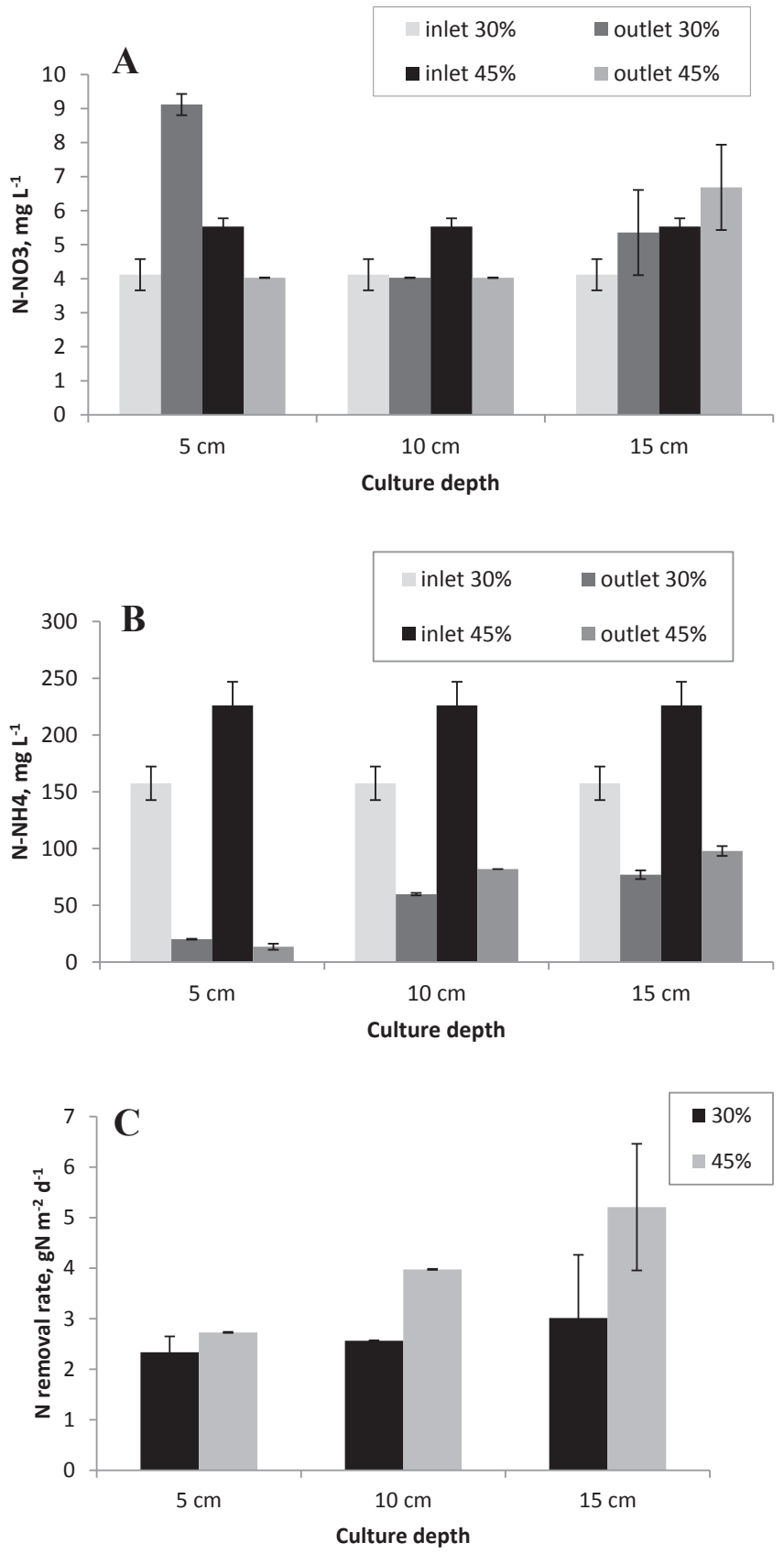

Fig. 4. Variation in nitrate (A), ammonium (B) inlet and outlet concentrations at $30 \%$ and $45 \%$ centrate and nitrogen removal rate (C) for Scenedesmus sp. culture as a function of the culture depth. Experiments were conducted in semicontinuous mode at $0.3 \mathrm{~d}^{-1}$.

With respect to phosphorus, Fig. 5 shows the variation in the phosphorus inlet and outlet with regard to the centrate percentage and the culture depth at $0.3 \mathrm{~d}^{-1}$. Similarly, the final phosphorus concentration increased as the centrate percentage and the culture depth increased. The highest phosphorus removal efficiency (90.6\%) was obtained at $0.3 \mathrm{~d}^{-1}$ at a $5 \mathrm{~cm}$ culture depth and $30 \%$ centrate, higher than $45.6 \%$ determined by Qi et al. (2018) from microalgae and bacteria co-culture using fermentation wastewater.

Regarding phosphorus removal rates (Fig. 5C), the results showed that no specific pattern was obvious in correlation with the centrate percentage, whereas it increased inversely with culture depth. The maximum phosphorus removal rate, $2.3 \mathrm{~g} \mathrm{P} \mathrm{m}^{-2} \mathrm{~d}^{-1}$, was obtained using $30 \%$ centrate at $0.3 \mathrm{~d}^{-1}$ with a $5 \mathrm{~cm}$ pond depth.

Nonetheless, the outlet concentrations for nitrogen and phosphorus
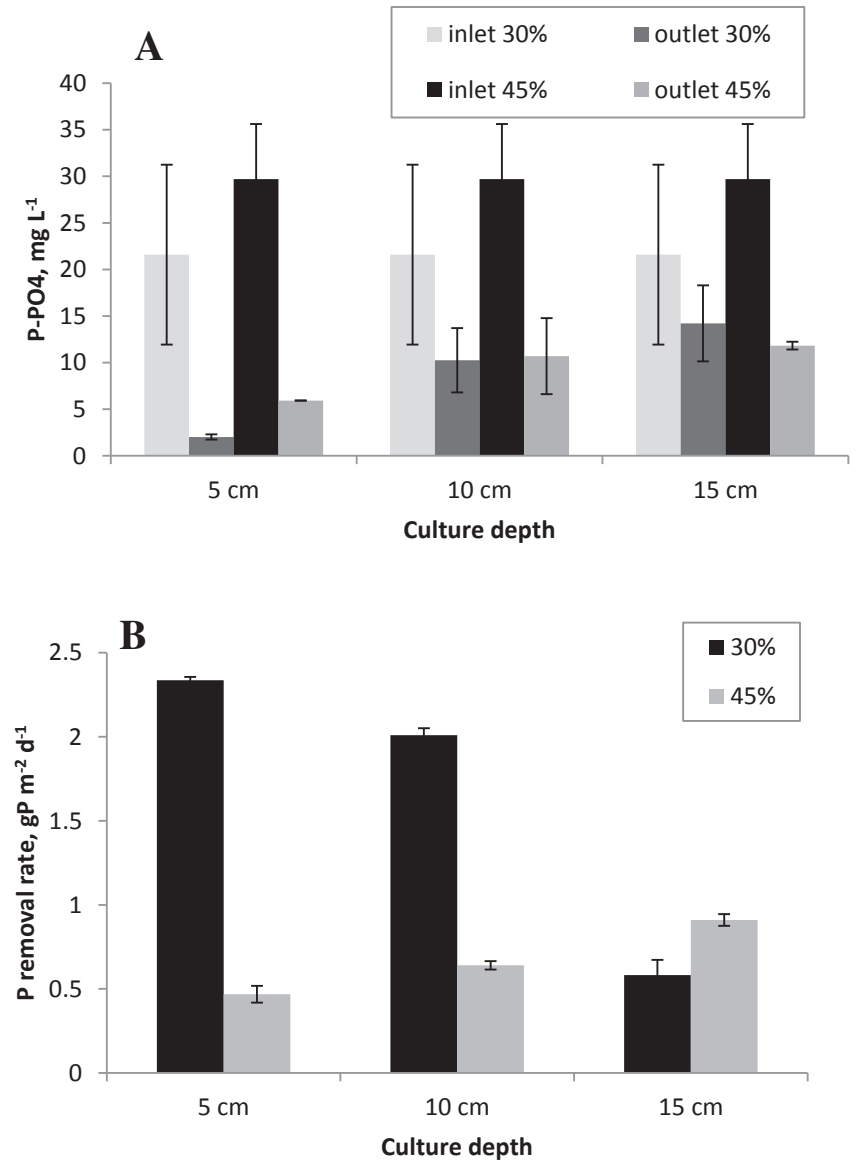

Fig. 5. Variation in phosphorus inlet and outlet at $30 \%$ and $45 \%$ centrate (A) and phosphorus removal rate (B) for Scenedesmus sp. culture as a function of the culture depth. Experiments were conducted in semi-continuous mode at $0.3 \mathrm{~d}^{-1}$.

reported here were higher than the standards permitted by European UnionDirective 98/15/CE, which regulates water release into the environment (10 $\mathrm{mg} \mathrm{N} / \mathrm{L}$ and $1 \mathrm{mg} \mathrm{P} / \mathrm{L}$ ).

Under optimal conditions for biomass productivity (30\% centrate, $0.3 \mathrm{~d}^{-1}$ of dilution rate and a $15 \mathrm{~cm}$ culture depth), up to $3.0 \mathrm{~g} \mathrm{~N} \mathrm{~m}^{-2} \mathrm{~d}^{-1}$ and $0.6 \mathrm{~g} \mathrm{P} \mathrm{m}^{-2} \mathrm{~d}^{-1}$ were removed. These values are within the $3.2 \mathrm{~g} \mathrm{~N} \mathrm{~m}^{-2} \mathrm{~d}^{-1}$ and $0.41 \mathrm{~g} \mathrm{P} \mathrm{m}^{-2} \mathrm{~d}^{-1}$ range reported from the cultivation of a microalgal-bacterial consortium using synthetic wastewater as the culture medium (Boelee et al., 2014), higher than the $1.0 \mathrm{~g} \mathrm{~N} \mathrm{~m}^{-2} \mathrm{~d}^{-1}$ and $0.13 \mathrm{~g} \mathrm{P} \mathrm{m}^{-2} \mathrm{~d}^{-1}$ obtained using real municipal wastewater for a microalgal consortium culture (Boelee et al., 2011) and the $2.1 \mathrm{~g}$ Total Kjeldhal Nitrogen $\mathrm{m}^{-2} \mathrm{~d}^{-1}$ determined from Chlorella sp. culture in a pilot-scale photobioreactor using a $1 / 4$ harvesting rate and utilizing centrate as the culture medium (Min et al., 2011).

In the light of the results obtained here, one can conclude that, although the $5 \mathrm{~cm}$ shallow pond provides higher values in terms of volumetric productivity and nutrient removal rates because of the short light path, deeper ponds are more commercially viable offering high areal productivity and nutrient uptake capacity. It has also been claimed that shallow ponds might exhibit greater temperature fluctuations compared to deep ponds (Sutherland et al., 2015) whereas very deep ponds might experience light limited problems. For instance, Sutherland et al. (2014) reported that a higher treated wastewater volume and areal productivity were achieved using a $400 \mathrm{~mm}$ culture depth than when using a $200 \mathrm{~mm}$-deep pond; whereas Silva Benavides et al. (2013) reported that limited solar radiation decreased the biomass productivity. As such, a compromise between culture depth and light 
availability in the pond should be considered in open raceway reactors in order to make this technology economically viable.

To sum up, the results presented here demonstrate that using centrate as the culture medium seems to be an economically feasible and viable option for reducing microalgae production costs and, consequently, ensuring process sustainability. Besides, this would significantly contribute, on the one hand, to wastewater treatment in conventional wastewater treatment plants by offering a cost-effective and eco-friendly bioremediation approach and, on the other hand, to the agricultural sector by recycling nutrients for soil amendments. Thus, a microalgae-based system provides an integrated process for nutrient recovery via wastewater treatment as well as a potentially viable source of biomass for low-value product application such as biofertilizers, feed and biofuels.

\section{Conclusion}

The native Scenedesmus sp. seems to be a good candidate for outdoor production using centrate. The optimal culture conditions were $30 \%$ centrate, $0.3 \mathrm{~d}^{-1}$ and $15 \mathrm{~cm}$ culture depth. A maximum biomass productivity of $22.9 \mathrm{~g} \mathrm{~m}^{-2} \mathrm{~d}^{-1}$ was obtained; corresponding to an estimated 80 tonnes ha $^{-1}$ year $^{-1}$, which is far greater than the productivity of oleaginous vegetal plants. The process could remove up to 10.8 tonnes $\mathrm{N} \mathrm{ha}^{-1}$ year $^{-1}$ and 2.2 tonnes $\mathrm{P} \mathrm{ha}^{-1}$ year $^{-1}$. Furthermore, $10.1 \%$ of lipids were determined corresponding to an estimated 8.3 tonnes ha ${ }^{-1}$ year $^{-1}$, along with a favorable fatty acids profile for biofuel production.

\section{Acknowledgements}

This work was supported by a grant from the Marine Microalgal Biotechnology group (BIO 173) of the Chemical Engineering Department, University of Almeria, Spain; EDARSOL CTQ2014-57293C3-1-R project. Juan Torres Castañeda and Juan Antonio Membrillas are acknowledged for their technical assistance. Thanks to Aqualia for providing us with the centrate samples and data about the average costs of wastewater treatment using activated sludge.

\section{Appendix A. Supplementary data}

Supplementary data associated with this article can be found, in the online version, at https://doi.org/10.1016/j.biortech.2018.04.057.

\section{References}

Acién Fernández, F.G., Fernández Sevilla, J.M., Molina Grima, E., 2013. Photobioreactors for the production of microalgae. Rev. Environ. Sci. Biotechnol. 12, 131-151.

Arbib, Z., Ruiz, J., Álvarez-Díaz, P., Garrido-Pérez, C., Perales, J.A., 2014. Capability of different microalgae species for phytoremediation processes: wastewater tertiary treatment, $\mathrm{CO}_{2}$ bio-fixation and low cost biofuels production. Water Res. 49 , 465-474.

Batista, A.P., Ambrosano, L., Graça, S., Sousa, C., Marques, P.A.S.S., Ribeiro, B., Botrel, E.P., Castro Neto, P., Gouveia, L., 2015. Combining urban wastewater treatment with biohydrogen production - an integrated microalgae-based approach. Bioresour. Technol. 184, 230-235.

Biller, P., Ross, A.B., 2011. Potential yields and properties of oil from the hydrothermal liquefaction of microalgae with different biochemical content. Bioresour. Technol. $102,215-225$.

Boelee, N.C., Temmink, H., Janssen, M., Buisman, C.J.N., Wijffels, R.H., 2014. Balancing the organic load and light supply in symbiotic microalgal-bacterial biofilm reactors treating synthetic municipal wastewater. Ecol. Eng. 64, 213-221.

Boelee, N.C., Temmink, H., Janssen, M., Buisman, C.J.N., Wijffels, R.H., 2011. Nitrogen and phosphorus removal from municipal wastewater effluent using microalgal biofilms. Water Res. 45, 5925-5933.

Cabanelas, I.T.D., Arbib, Z., Chinalia, F.A., Souza, C.O., Perales, J.A., Almeida, P.F. Druzian, J.I., Nascimento, I.A., 2013a. From waste to energy: microalgae production in wastewater and glycerol. Appl. Energy 109, 283-290.

Cabanelas, I.T.D., Ruiz, J., Arbib, Z., Chinalia, F.A., Garrido-Pérez, C., Rogalla, F., Nascimento, I.A., Perales, J.A., 2013b. Comparing the use of different domestic wastewaters for coupling microalgal production and nutrient removal. Bioresour. Technol. 131, 429-436.

Cai, T., Park, S.Y., Li, Y., 2013. Nutrient recovery from wastewater streams by microalgae: status and prospects. Renewable Sustainable Energy Rev. 19, 360-369.

Chinnasamy, S., Bhatnagar, A., Claxton, R., Das, K.C., 2010a. Biomass and bioenergy production potential of microalgae consortium in open and closed bioreactors using untreated carpet industry effluent as growth medium. Bioresour. Technol. 101, 6751-6760.

Chinnasamy, S., Bhatnagar, A., Hunt, R.W., Das, K.C., 2010b. Microalgae cultivation in a wastewater dominated by carpet mill effluents for biofuel applications. Bioresour. Technol. 101, 3097-3105.

Chisti, Y., 2012. Microalgal biotechnology: potential and production. In: Clemens, P., Christian, W. (Eds.), Microalgal Biotechnology: Potential and Production. DeGruyter, Göttingen, pp. 113-146.

Chiu, S.-Y., Kao, C.-Y., Huang, T.-T., Lin, C.-J., Ong, S.-C., Chen, C.-D., Chang, J.-S., Lin, C.-S., 2011. Microalgal biomass production and on-site bioremediation of carbon dioxide, nitrogen oxide and sulfur dioxide from flue gas using Chlorella sp. cultures. Bioresour. Technol. 102, 9135-9142.

He, P.J., Mao, B., Shen, C.M., Shao, L.M., Lee, D.J., Chang, J.S., 2013. Cultivation of Chlorella vulgaris on wastewater containing high levels of ammonia for biodiesel production. Bioresour. Technol. 129, 177-181.

Hoekman, S.K., Broch, A., Robbins, C., Ceniceros, E., Natarajan, M., 2012. Review of biodiesel composition, properties, and specifications. Renewable Sustainable Energy Rev. 16, 143-169.

Ichimura, T., Itoh, T., 1977. Preservation methods of microalgae (I). In: Nei, T. (Ed.), Preservation Methods of Microorganisms. University of Tokyo Press, Tokyo, pp. 355-373.

Jebali, A., Acién, F.G., Sayadi, S., Molina-Grima, E., 2018. Utilization of centrate from urban wastewater plants for the production of Scenedesmus sp. in a raceway-simulating reactor. J. Environ. Manage. 211, 112-124.

Jebali, A., Acién, F.G., Gómez, C., Fernández-Sevilla, J.M., Mhiri, N., Karray, F., Dhouib, A., Molina-Grima, E., Sayadi, S., 2015. Selection of native Tunisian microalgae for simultaneous wastewater treatment and biofuel production. Bioresour. Technol. 198, 424-430.

Ji, M.-K., Abou-Shanab, R.A.I., Kim, S.-H., Salama, E.-S., Lee, S.-H., Kabra, A.N., Lee, Y.S., Hong, S., Jeon, B.-H., 2013. Cultivation of microalgae species in tertiary municipal wastewater supplemented with $\mathrm{CO}_{2}$ for nutrient removal and biomass production. Ecol. Eng. 58, 142-148.

Kochert, G., 1978. Handbook of Phycological Methods: Culture Methods and Growth Measurements, first ed. Cambridge University Press, London.

Li, Y., Chen, Y.-F., Chen, P., Min, M., Zhou, W., Martinez, B., Zhu, J., Ruan, R., 2011. Characterization of a microalga Chlorella sp. well adapted to highly concentrated municipal wastewater for nutrient removal and biodiesel production. Bioresour. Technol. 102, 5138-5144.

Maestrini, S.Y., Robert, J.-M., Leftley, J.W., Collos, Y., 1986. Ammonium thresholds for simultaneous uptake of ammonium and nitrate by oyster-pond algae. J. Exp. Mar. Biol. Ecol. 102, 75-98.

Matamoros, V., Gutiérrez, R., Ferrer, I., García, J., Bayona, J.M., 2015. Capability of microalgae-based wastewater treatment systems to remove emerging organic contaminants: a pilot-scale study. J. Hazard. Mater. 288, 34-42.

McGinn, P.J., Dickinson, K.E., Park, K.C., Whitney, C.G., MacQuarrie, S.P., Black, F.J., Frigon, J.-C., Guiot, S.R., O'Leary, S.J.B., 2012. Assessment of the bioenergy and bioremediation potentials of the microalga Scenedesmus sp. AMDD cultivated in municipal wastewater effluent in batch and continuous mode. Algal Res. 1, 155-165.

Min, M., Hu, B., Mohr, M.J., Shi, A., Ding, J., Sun, Y., Jiang, Y., Fu, Z., Griffith, R., Hussain, F., Mu, D., Nie, Y., Chen, P., Zhou, W., Ruan, R., 2014. Swine manure-based pilot-scale algal biomass production system for fuel production and wastewater treatment - a case study. Appl. Biochem. Biotechnol. 172, 1390-1406.

Min, M., Wang, L., Li, Y., Mohr, M.J., Hu, B., Zhou, W., Chen, P., Ruan, R., 2011. Cultivating Chlorella sp. in a pilot-scale photobioreactor using centrate wastewater for microalgae biomass production and wastewater nutrient removal. Appl. Biochem. Biotechnol. 165, 123-137.

Ministry of Agriculture, 1982. Ministry of Agriculture, Official Methods of Analysis: Soil and Water. Ministry of Agriculture, General Technical Secretary, Madrid.

Molina Grima, E., García Camacho, F., Sánchez Pérez, J.A., Acién Fernández, F.G., Fernández Sevilla, J.M., 1997. Evaluation of photosynthetic efficiency in microalgal cultures using averaged irradiance. Enzyme Microb. Technol. 21, 375-381.

Morales-Amaral, M., Gómez-Serrano, C., Acién, F.G., Fernández-Sevilla, J.M., MolinaGrima, E., 2015a. Outdoor production of Scenedesmus sp. in thin-layer and raceway reactors using centrate from anaerobic digestion as the sole nutrient source. Algal Res. 12, 99-108.

Morales-Amaral, M., Gómez-Serrano, C., Acién, F.G., Fernández-Sevilla, J.M., MolinaGrima, E., 2015b. Production of microalgae using centrate from anaerobic digestion as the nutrient source. Algal Res. 9, 297-305.

Osundeko, O., Pittman, J.K., 2014. Implications of sludge liquor addition for wastewaterbased open pond cultivation of microalgae for biofuel generation and pollutant remediation. Bioresour. Technol. 152, 355-363.

Park, J.B.K., Craggs, R.J., Shilton, A.N., 2013. Enhancing biomass energy yield from pilotscale high rate algal ponds with recycling. Water Res. 47, 4422-4432.

Park, J.B.K., Craggs, R.J., Shilton, A.N., 2011. Wastewater treatment high rate algal ponds for biofuel production. Bioresour. Technol. 102, 35-42.

Pittman, J.K., Dean, A.P., Osundeko, O., 2011. The potential of sustainable algal biofuel production using wastewater resources. Bioresour. Technol. 102, 17-25.

Qi, W., Mei, S., Yuan, Y., Li, X., Tang, T., Zhao, Q., Wu, M., Wei, W., Sun, Y., 2018. Enhancing fermentation wastewater treatment by co-culture of microalgae with volatile fatty acid- and alcohol-degrading bacteria. Algal Res. 31, 31-39.

Rawat, I., Ranjith Kumar, R., Mutanda, T., Bux, F., 2011. Dual role of microalgae: phycoremediation of domestic wastewater and biomass production for sustainable biofuels production. Appl. Energy 88, 3411-3424. 
Rinna, F., Buono, S., Cabanelas, I.T.D., Nascimento, I.A., Sansone, G., Barone, C.M.A., 2017. Wastewater treatment by microalgae can generate high quality biodiesel feedstock. J. Water. Process. Eng. 18, 144-149.

Rodríguez-Ruiz, J., Belarbi, E.-H., Sánchez, J.L.G., Alonso, D.L., 1998. Rapid simulta neous lipid extraction and transesterification for fatty acid analyses. Biotechnol. Tech. 12, 689-691.

Ruiz-Martinez, A., Martin Garcia, N., Romero, I., Seco, A., Ferrer, J., 2012. Microalgae cultivation in wastewater: nutrient removal from anaerobic membrane bioreactor effluent. Bioresour. Technol. 126, 247-253.

Sepúlveda, C., Acién, F.G., Gómez, C., Jiménez-Ruíz, N., Riquelme, C., Molina-Grima, E., 2015. Utilization of centrate for the production of the marine microalgae Nannochloropsis gaditana. Algal Res. 9, 107-116.

Silva Benavides, A.M., Torzillo, G., Kopecký, J., Masojídek, J., 2013. Productivity and biochemical composition of Phaeodactylum tricornutum (Bacillariophyceae) cultures grown outdoors in tubular photobioreactors and open ponds. Biomass Bioenergy 54, $115-122$.

Sutherland, D.L., Howard-Williams, C., Turnbull, M.H., Broady, P.A., Craggs, R.J., 2015. Enhancing microalgal photosynthesis and productivity in wastewater treatment high rate algal ponds for biofuel production. Bioresour. Technol. 184, 222-229.

Sutherland, D.L., Turnbull, M.H., Craggs, R.J., 2014. Increased pond depth improves algal productivity and nutrient removal in wastewater treatment high rate algal ponds. Water Res. 53, 271-281.

Sydney, E.B., da Silva, T.E., Tokarski, A., Novak, A.C., de Carvalho, J.C., Woiciecohwski,
A.L., Larroche, C., Soccol, C.R., 2011. Screening of microalgae with potential for biodiesel production and nutrient removal from treated domestic sewage. Appl. Energy 88, 3291-3294.

Wang, L., Min, M., Li, Y., Chen, P., Chen, Y., Liu, Y., Wang, Y., Ruan, R., 2010. Cultivation of green algae Chlorella sp. in different wastewaters from municipal wastewater treatment plant. Appl. Biochem. Biotechnol. 162, 1174-1186.

Yang, J., Xu, M., Zhang, X., Hu, Q., Sommerfeld, M., Chen, Y., 2011. Life-cycle analysis on biodiesel production from microalgae: water footprint and nutrients balance. Bioresour. Technol. 102, 159-165.

Zhou, W., Li, Y., Min, M., Hu, B., Zhang, H., Ma, X., Li, L., Cheng, Y., Chen, P., Ruan, R. 2012a. Growing wastewater-born microalga Auxenochlorella protothecoides UMN280 on concentrated municipal wastewater for simultaneous nutrient removal and energy feedstock production. Appl. Energy 98, 433-440.

Zhou, W., Min, M., Li, Y., Hu, B., Ma, X., Cheng, Y., Liu, Y., Chen, P., Ruan, R., 2012b. A hetero-photoautotrophic two-stage cultivation process to improve wastewater nutrient removal and enhance algal lipid accumulation. Bioresour. Technol. 110, $448-455$.

Zhu, L., Nugroho, Y.K., Shakeelb, S.R., Li, Z., Martinkauppi, B., Hiltunen, E., 2017. Using microalgae to produce liquid transportation biodiesel: what is next? Renewable Sustainable Energy Rev. 78, 391-400.

Zhu, L.-D., Hiltunen, E., 2016. Application of livestock waste compost to cultivate microalgae for bioproducts production: a feasible framework. Renewable Sustainable Energy Rev. 54, 1285-1290. 